\title{
Combination of fluvastatin and losartan relieves atherosclerosis and macrophage infiltration in atherosclerotic plaques in rabbits
}

\author{
Ya-pei YANG 1, 2, 4, \#, Qiu-li DONG 1, 3, 4, \#, Xu-hong ZHANG ${ }^{1}$, Yue-hui ZHANG ${ }^{1}$, Li ZHUU 1,4, Shu-ying LI ${ }^{1,4,5}$, Zhong-zhi LIU ${ }^{1}$, \\ Hui XU ${ }^{1,4,5}$, Nan WANG ${ }^{1,4}$, Hong JIANG ${ }^{4}$, Chun-xi LIU ${ }^{4}$, Xian-xi LIU², * , Bo DONG ${ }^{1,4,5, *}$ \\ ${ }^{1}$ Department of Cardiology, Provincial Hospital Affiliated to Shandong University, Shandong University, Ji-nan 250021, China; ${ }^{2}$ Institute \\ of Biochemistry and Molecular Biology, School of Medicine, Shandong University, Ji-nan 250012, China; ${ }^{3}$ Department of Cardiology, \\ General Hospital of Huabei Petroleum Company, Renqiu 062552, China; ${ }^{4}$ The Key Laboratory of Cardiovascular Remodeling and \\ Function Research, Chinese Ministry of Education and Chinese Ministry of Health, Shandong University Qilu Hospital, Ji-nan 250012, \\ China; ${ }^{5}$ Shandong Provincial Key Laboratory of Diagnosis and Treatment of Cardio-cerebral Vascular Disease, Ji-nan 250021, China
}

Aim: To investigate whether the combination of fluvastatin and losartan synergistically relieve atherosclerosis and plaque inflammation induced by a high-cholesterol diet in rabbits.

Methods: Atherosclerosis was induced with a high-cholesterol diet for 3 months in 36 New Zealand white rabbits. The animals were randomly divided into model group, fluvastatin (10 $\left.\mathrm{mg} \cdot \mathrm{kg}^{-1} \cdot \mathrm{d}^{-1}\right)$ group, losartan $\left(25 \mathrm{mg} \cdot \mathrm{kg}^{-1} \cdot \mathrm{d}^{-1}\right)$ group, and fluvastatin plus losartan group. After the 16-week treatments, the blood samples the animals were collected, and the thoracic aortas were examined immunohistochemically. The mRNA and protein expression levels of monocyte chemotactic protein-1 (MCP-1) were measured using RT-PCR and Western blot.

Results: Compared to the treatment with losartan or fluvastatin alone, the combined treatment did not produce higher efficacy in reduction of blood cholesterol level. However, the combination did synergistically decrease the intimal and media thickness of thoracic aortas with significantly reduced macrophage infiltration and MCP-1 expression in the plaques.

Conclusion: The combined treatment with losartan and fluvastatin significantly inhibited atherosclerotic progress and reduced inflammation associated with atherosclerotic plaques.

Keywords: Iosartan; fluvastatin; cholesterol; atherosclerosis; macrophages; monocyte chemotactic protein-1 (MCP-1); inflammation; p38 MAPK; smooth muscle cells

Acta Pharmacologica Sinica (2011) 32: 1259-1265; doi: 10.1038/aps.2011.95; published online 12 Sep 2011

\section{Introduction}

A growing body of evidence has suggested that blood lipid metabolism disorders and angiotensin II (Ang II) have synergistic effects on the occurrence of atherosclerosis, and the combination of dyslipidemia and the activation of the reninangiotensin system (RAS) plays an important role in the pathogenesis of atherogenesis ${ }^{[1]}$. Oxidized low-density lipoprotein (ox-LDL) can upregulate the expression of the angiotensin II type 1 receptor (AT1R) on the surface of endothelial cells and macrophages ${ }^{[2-4]}$. Ang II facilitates LDL oxidization

\footnotetext{
\# The first two authors contributed equally to this work.

* To whom correspondence should be addressed.

E-mail dongbo1@medmail.com.cn (Bo DONG); xianxi@sdu.edu.cn (Xian-xi LIU)

Received 2011-06-08 Accepted 2011-06-27
}

and uptake by endothelial cells, smooth muscle cells and macrophages ${ }^{[5]}$.

Angiotensin II also increases the oxidative stress response, which leads to the production of reactive oxygen species (ROS) and the aggravation of atherosclerosis. It is common to use a combination of a statin and an angiotensin II type 1 receptor blocker $(A R B)$ to treat hypertensive patients with lipid metabolism disorders. However, few studies have been reported in regards to the underlying molecular mechanisms. Recent studies have shown that the combination of an HMGCoA (3-hydroxy-3-methylglutaryl-coenzyme A) reductase inhibitor and an ARB has a better effect on relieving the severity of atherosclerosis and down-regulating the expression of lectin-like oxidized low density lipoprotein receptor-1 (LOX1 ) than the use of a single drug ${ }^{[6]}$. Our previous study showed that angiotensin II plays an important role in the pathogenesis 
of atherosclerosis ${ }^{[7,8]}$. In addition, Han et al and Koh et al also demonstrated that the combination of simvastatin and losartan has vascular protective effects ${ }^{[9,10]}$. These studies indicated that the combination of simvastatin and losartan may play an important role in preventing the progression of coronary heart disease. However, little is known about the exact role of the combination of statins and ARBs in the formation of atherosclerotic plaques and its effect on the inflammation of plaques. With these considerations in mind, our present study was designed to develop an atherosclerosis model by feeding rabbits with high-fat food and to investigate the effects and mechanisms of the combinational use of fluvastatin and losartan on the development of atherosclerosis and inflammation within the atherosclerotic plaques.

\section{Materials and methods} Atherosclerosis model

New Zealand white rabbits (weight: $1.5-1.63 \mathrm{~kg}$ ) were provided by the Institute of Animal Science and Veterinary Medicine, Shandong Academy of Agriculture Sciences (Shandong, China). The rabbits $(n=36)$ were provided with regular food for 1 week and were subsequently provided with highcholesterol food ( $1 \%$ cholesterol and $5 \%$ pig oil particles) for 3 months to generate the atherosclerosis model. The 36 rabbits were randomly divided into 4 groups. The high-cholesterol group $(\mathrm{CH})$ contained rabbits $(n=9)$ that were provided with high-cholesterol food without other treatments. The fluvastatin group $(\mathrm{F})$ contained rabbits $(n=9)$ that were provided with high-cholesterol food and fluvastatin $\left(10 \mathrm{mg} \cdot \mathrm{kg}^{-1} \cdot \mathrm{d}^{-1}\right)$ (Novartis, Beijing, China). The losartan group (L) contained rabbits $(n=9)$ that were provided with high-cholesterol food and losartan $\left(25 \mathrm{mg} \cdot \mathrm{kg}^{-1} \cdot \mathrm{d}^{-1}\right)$ (Merck Sharp \& Dohme, Hangzhou, China). The fluvastatin and losartan combination group $(\mathrm{F}+\mathrm{L})$ contained rabbits $(n=9)$ that were provided with highcholesterol food and treated with a combination of fluvastatin $\left(10 \mathrm{mg} \cdot \mathrm{kg}^{-1} \cdot \mathrm{d}^{-1}\right)$ and losartan $\left(25 \mathrm{mg} \cdot \mathrm{kg}^{-1} \cdot \mathrm{d}^{-1}\right)$. Both drugs were administered in the food ${ }^{[11-13]}$. An additional 8 rabbits were provided with regular food to act as a negative control group for comparison with the occurrence of atherosclerotic plaques induced by high-cholesterol food.

\section{Total cholesterol and LDL-cholesterol analysis}

Blood samples were drawn from the marginal ear vein after the 16-week treatment period. Total cholesterol (TC) and LDL-cholesterol concentrations were evaluated by enzymatic assays (Sigma Diagnostics).

\section{Pathological examination and immunohistochemistry}

The rabbits were anesthetized by an intramuscular injection of ketamine $(35 \mathrm{mg} / \mathrm{kg}) /$ xylazine $(7 \mathrm{mg} / \mathrm{kg})$ and local anesthesia of the inguinal region by lidocaine. The thoracic aorta was separated, and the upper section was stored in liquid nitrogen. The lower sections of the arteries were fixed in $4 \%$ formaldehyde and embedded in paraffin. Sections $(5 \mu \mathrm{m})$ were cut for the analyses of macrophage infiltration, smooth muscle cells (SMCs) and MCP-1 expression. Macrophage infiltration, smooth muscle cells (SMCs) and MCP-1 protein expression were measured by immunohistochemistry. In the macrophage infiltration analysis, the sections were incubated with mouse anti-macrophage antibody (RAM11) (DAKO, USA). The SMCs and MCP-1 protein were incubated with mouse antihuman antibody (Santa Cruz, USA). The first antibody was cultured overnight at $4{ }^{\circ} \mathrm{C}$. After extensive washing, the sections were incubated with biotin-conjugated goat anti-mouse IgG antibody. Visualization of the sections was performed with the SABC staining kit (Santa Cruz, USA). Staining for the macrophages, MCP-1 and SMCs was performed in a similar way. A customized imaging analysis system (Image-Pro Plus 5.0, Media Cybernetics, USA) was used to analyze the immunohistochemical results. The thickness of the intima and media of the thoracic aortas and positive staining in immunohistochemistry were analyzed using the imaging processing software.

\section{RT-PCR}

The total RNA was extracted from the rabbits in each group using the Trizol kit (Invitrogen, Carlsbad, CA). The concentration of RNA was measured by an ultraviolet spectrophotometer. Reverse transcription was performed in a total volume of $20 \mu \mathrm{L}$. The total RNA $(1.5 \mu \mathrm{L})$ was mixed with DEPC water $(8 \mu \mathrm{L})$ and denatured at $72{ }^{\circ} \mathrm{C}$ for $10 \mathrm{~min}$ followed by incubation on ice for $5 \mathrm{~min}$. The RNase inhibitor (50 U/L) $(0.5$ $\mu \mathrm{L})$, reverse transcriptase (M-MLV 5U/L) $(1 \mu \mathrm{L}), \mathrm{MgCl}_{2}(25$ $\mathrm{mmol} / \mathrm{L}, 4 \mu \mathrm{L})$, dNTP $(10 \mathrm{mmol} / \mathrm{L}, 2 \mu \mathrm{L}), 10 \times$ buffer $(2 \mu \mathrm{L})$ and OligodT ( $2.5 \mathrm{pmol} / \mathrm{L}, 1 \mu \mathrm{L}$ ) were added to the denatured RNA samples and incubated at $42^{\circ} \mathrm{C}$ for $30 \mathrm{~min}, 99^{\circ} \mathrm{C}$ for $5 \mathrm{~min}$ and $5^{\circ} \mathrm{C}$ for $5 \mathrm{~min}$. PCR was performed in a total volume of $50 \mu \mathrm{L}$ containing $1.5 \mu \mathrm{L}$ of reverse transcription products (cDNA), $0.5 \mu \mathrm{L}$ of DNA polymerase ( $5 \mathrm{U} / \mathrm{L}), 5 \mu \mathrm{L}$ of $10 \times$ buffer, $4 \mu \mathrm{L}$ of $\mathrm{dNTP}(2.5 \mathrm{mmol} / \mathrm{L}), 4 \mu \mathrm{L} \mathrm{MgCl}_{2}(25 \mathrm{mmol} / \mathrm{L})$ and $1 \mu \mathrm{L}$ of each forward and reverse primers. The sequences of the forward and reverse primers for the amplification of the MCP-1 gene (330 bp) were 5'-TGCTCATTCCATACAGCCTGTG-3' and 5'-CTTTTCATGCTTAGCGGCG-3', respectively. The sequences of the forward and reverse primers for the amplification of the GAPDH gene (476 bp) were 5'-GAGCTGAACGGGAAACTCAC-3 and 5'-GGTCTGGGATGGAAACTGTG-3', respectively. All of the primers were synthesized by Shanghai Sangon Biological Engineering Technology Co, LTD (Shanghai, China). The parameters for the PCR reaction were $94{ }^{\circ} \mathrm{C}$ for $4 \mathrm{~min}$ followed by 40 cycles of $94^{\circ} \mathrm{C}$ for $30 \mathrm{~s}, 55^{\circ} \mathrm{C}$ for $45 \mathrm{~s}, 72{ }^{\circ} \mathrm{C}$ for $1 \mathrm{~min}$ and a final extension of $72{ }^{\circ} \mathrm{C}$ for $10 \mathrm{~min}$. The PCR products were electrophoresed on a $1.5 \%$ agarose gel. The PCR products of the GAPDH gene were used as an internal control, and the relative expression of the MCP-1 gene was calculated as an OD value of the MCP-1 PCR products/ GAPDH products.

\section{Western blot}

The aortic tissues were homogenized in a Tris- $\mathrm{HCl}$ buffer and centrifuged at $4000 \mathrm{r} / \mathrm{min}$ for $10 \mathrm{~min}$ at $4{ }^{\circ} \mathrm{C}$. Protein concentrations were determined using a bicinchoninic acid protein 
assay. The lysate proteins from the aortas were separated with 10\% SDS-PAGE gels and were subsequently transferred onto nitrocellulose membranes. After being blocked with 5\% non-fat milk, the membranes were incubated with primary antibodies to mouse p38 MAPK (Cell Signaling Technology) followed by the corresponding horseradish peroxidase-conjugated secondary antibodies. The bands were visualized by an MSF-300G Scanner (Microtek Lab, Nikon, Japan).

\section{Statistical analysis}

Data were analyzed using an ANOVA procedure. A $P<0.05$ was considered statistically significant. Data were presented as the mean \pm SD. SPSS for Windows Version 10.0 (SPSS Inc, Chicago, IL, USA) was used for the statistical analysis.

\section{Results}

\section{Blood cholesterol level}

After 4 months of high-fat feeding, the administration of fluvastatin alone and the combination of fluvastatin and losartan decreased the total cholesterol and LDL-cholesterol levels $(P<0.01)$. The total cholesterol and LDL-cholesterol levels were not significantly different between the losartan group and the high-cholesterol group, indicating that losartan alone had no significant effect on the total cholesterol and LDLcholesterol levels (Figure 1A, 1B).

\section{The effects of fluvastatin and losartan on plaque morphology}

To further study the inhibitory effects of fluvastatin and losartan on atherosclerosis, we measured the intimal thicknesses, the ratio of intima to media thickness (I/M) and the lipid content after treatment with fluvastatin and losartan. The intimal thickness and the ratios of intima to media thickness (I/M) were lower in the individual fluvastatin and losartan groups than in the high-cholesterol group $(P<0.01$, Figure $1 C$, 1D, Table 1). The intimal thickness and the ratio of intima to media thickness (I/M) were further decreased by the combination of the two agents $(P<0.01)$ [note that the combination of fluvastatin and losartan had a greater atherosclerosis-
Table 1. The intimal thickness and the ratio of intima to media thickness (I/ M) in the four groups. Mean \pm SD. $n=9 .{ }^{c} P<0.01$ vs HC group. ${ }^{f} P<0.01$ vs fluvastatin group. ${ }^{i} P<0.01$ vs losartan group.

\begin{tabular}{lcc}
\hline Group & $\begin{array}{c}\text { The intimal } \\
\text { thickness }(\mu \mathrm{m})\end{array}$ & $\begin{array}{c}\text { The ratio of intima } \\
\text { to media } \\
\text { thickness }(\mathrm{I} / \mathrm{M})\end{array}$ \\
\hline $\mathrm{HC}$ & $536.81 \pm 87.04$ & $1.37 \pm 0.15$ \\
$\mathrm{~F}$ & $281.43 \pm 28.47^{\mathrm{c}}$ & $0.80 \pm 0.06^{\mathrm{c}}$ \\
$\mathrm{L}$ & $316.21 \pm 38.31^{\mathrm{c}}$ & $0.87 \pm 0.03^{\mathrm{c}}$ \\
$\mathrm{F}+\mathrm{L}$ & $228.70 \pm 22.96^{\mathrm{fi}}$ & $0.66 \pm 0.04^{\mathrm{fi}}$ \\
\hline
\end{tabular}

reducing effect than fluvastatin or losartan alone (Figure $1 \mathrm{C}$, 1D, Table 1)]. The lipid contents were statistically lower in the individual fluvastatin and losartan groups than in the highcholesterol group $(P<0.01)$. Furthermore, the lipid content was markedly lower in the combination group than in the individual fluvastatin and losartan groups $(P<0.01$, Figure $2 \mathrm{~A}, 2 \mathrm{~B})$.

The effect of the combination of fluvastatin and losartan on decreasing macrophages in atherosclerotic plaques

To further study the effect of fluvastatin and losartan on regulating macrophages in atherosclerotic plaques, we performed immunohistochemical analysis and observed macrophage changes after treatment with fluvastatin and losartan. A large number of macrophages were present in the atherosclerotic plaques of the high-cholesterol group compared to the fluvastatin group and the losartan group, which demonstrated a small number of macrophages. This indicated that fluvastatin or losartan alone was able to reduce macrophage infiltration in the atherosclerotic plaques $(P<0.01$, Figure $2 \mathrm{C}, 3 \mathrm{~B}$, Table $2)$. The macrophages in atherosclerotic plaques were further reduced by the combination of fluvastatin and losartan, which demonstrated that the combinational treatment had a greater macrophage-reduction activity within the atherosclerotic plaques $(P<0.01$, Figure $2 \mathrm{C}, 3 \mathrm{~B}$, Table 2$)$.
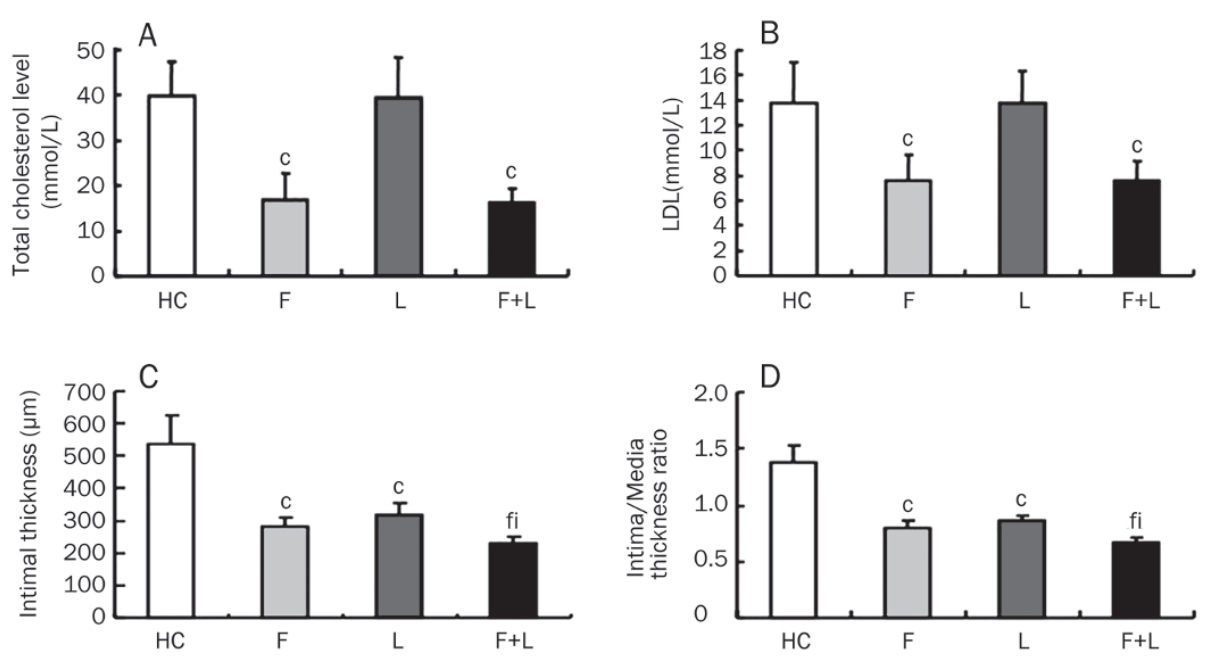

Figure 1. The effect of fluvastatin and losartan on plasma lipid levels and the extent of atherosclerosis. (A) The total cholesterol levels. (B) The LDL-cholesterol levels. (C) The intimal thickness in four groups. (D) The ratio of intima to media thickness $(\mathrm{I} / \mathrm{M})$ in four groups. ${ }^{\mathrm{C}} P<0.01$ vs HC-diet group; ${ }^{\mathrm{f}} P<0.01$ vs fluvastatin group; ' $P<0.01$ vs losartan group. Mean \pm SD. $n=9$. 
A

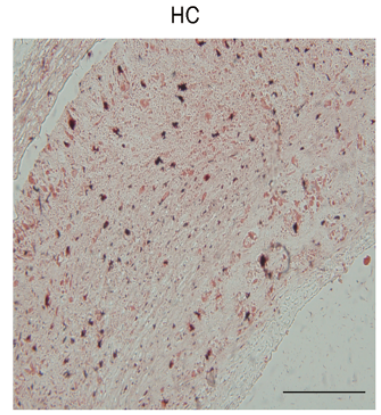

$\mathrm{F}$

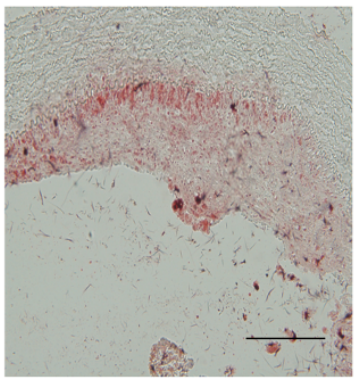

L

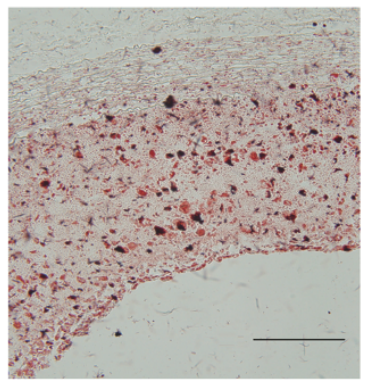

$\mathrm{F}+\mathrm{L}$

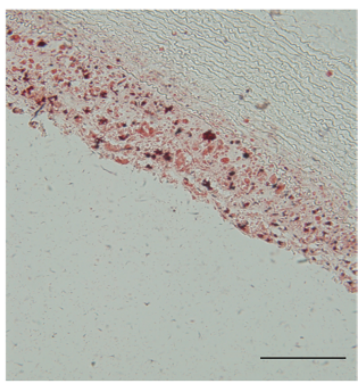

B

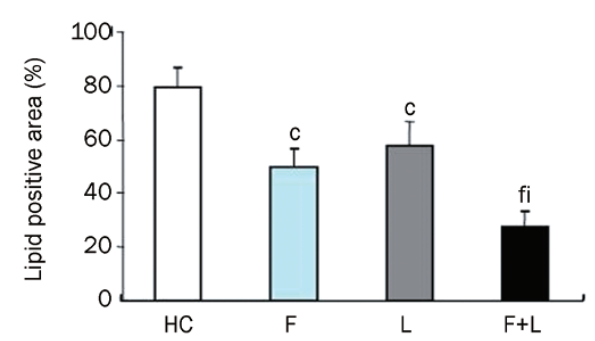

C

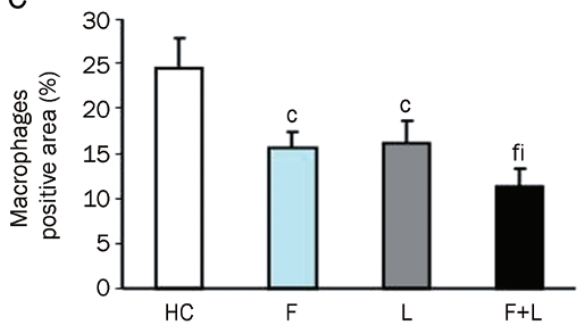

Figure 2. Oil Red 0 staining and macrophages in atherosclerotic plaques. (A) Oil Red 0 staining in atherosclerotic plaques in the four groups (magnification $\times 10$, scale bars equal $200 \mu \mathrm{m}$ ). (B) Quantification of the positive staining area. ${ }^{\mathrm{C}} P<0.01$ vs HC-diet group; ${ }^{\mathrm{f}} P<0.01$ vs fluvastatin group; ${ }^{\mathrm{i}} P<0.01 \mathrm{vs}$ losartan group. Data are the mean \pm SD. (C) Quantification of the macrophages that stained positive in the plaques. ${ }^{\mathrm{C}} P<0.01 \mathrm{vs} \mathrm{HC}$-diet group; ${ }^{\mathrm{f}} \mathrm{P}<0.01$ vs fluvastatin group; ' $P<0.01$ vs losartan group. Mean \pm SD. $n=9$.

Table 2. Quantification of the macrophages that stain positive in the plaques. The results are expressed as the mean \pm SD. $n=9 .{ }^{\circ} P<0.01$ vs HC group. ${ }^{f} P<0.01$ vs fluvastatin group. ${ }^{i} P<0.01$ vs losartan group.

\begin{tabular}{lc}
\hline Group & Macrophages positive (\%) \\
\hline HC & $24.47 \pm 3.44$ \\
F & $15.66 \pm 1.66^{\circ}$ \\
\hline
\end{tabular}

\section{The effect of fluvastatin and losartan on MCP-1 expression in the} four groups

To study the role of fluvastatin and losartan in the inhibition of MCP-1 expression, we performed an experiment to determine the expression of MCP-1 at both the protein and mRNA levels. The MCP-1 protein expression level was reduced by fluvastatin and losartan alone as compared to an HC-diet group $(P<0.01)$. The expression of the MCP-1 protein was fur-
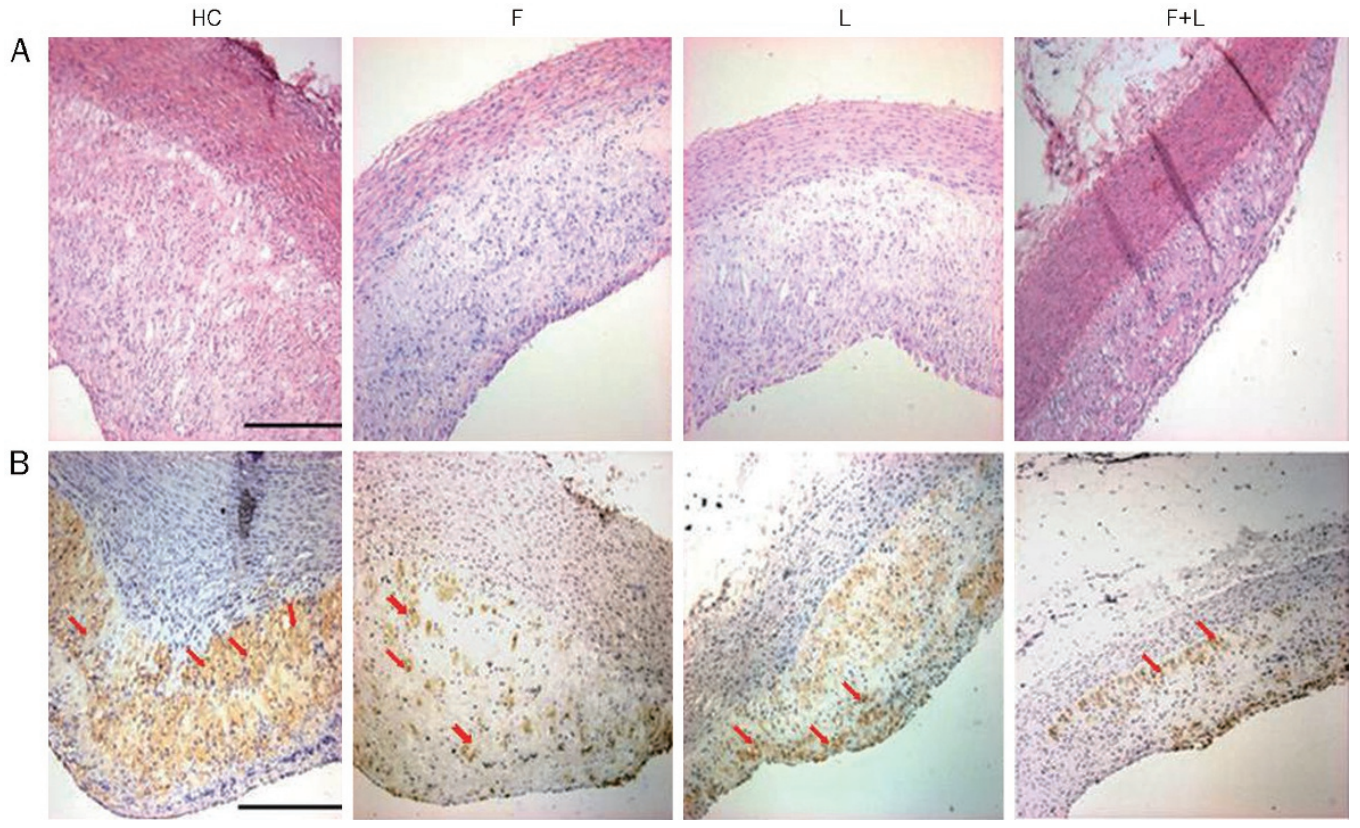

Figure 3. HE staining and morphological analysis in plaques in the four groups. (A) HE staining in the HC-diet group (HC), fluvastatin group $(F)$, losartan group (L), fluvastatin and losartan group $(\mathrm{F}+\mathrm{L})$. (magnification $\times 10$, scale bars equal $200 \mu \mathrm{m}$ ). (B) Macrophage expression in the $\mathrm{HC}$-diet group (HC), fluvastatin group (F), losartan group (L), fluvastatin and losartan group $(F+L)$ in plaques by immunohistochemical staining. (magnification $\times 10$, scale bars equal $200 \mu \mathrm{m}$ ). 
ther reduced by the combinational treatment with fluvastatin and losartan $(P<0.05)$, which indicated that the combination of the two agents had a synergistic inhibitory effect on MCP-1 protein expression (Figure 4A, 4B). A similar inhibitory effect was observed for MCP-1 gene expression (Figure 4C, 4D).

\section{SMC expression in the four groups}

The proliferation and migration of SMCs is one feature of early atherosclerotic lesions. To study the effect of fluvastatin or losartan on the expression of SMCs in atherosclerotic plaques, we observed a-actin-positive vascular smooth muscle cells in atherosclerotic plaques among the four groups. There were no significant differences among the four groups (Figure 5A).

\section{p38 MAPK protein expression in the four groups}

Western blot analysis showed that p38 MAPK protein expression was present in the atherosclerotic plaques of the highcholesterol group. Both fluvastatin and losartan alone significantly attenuated p38 MAPK expression $(P<0.05$ vs the HCdiet group). Furthermore, the combination of fluvastatin and losartan further reduced p38 MAPK protein expression within the plaques compared to either fluvastatin or losartan alone $(P<0.05$ vs fluvastatin or losartan alone) (Figure 5B, 5C).

\section{Discussion}

In this study, we explored the effect of fluvastatin or losartan and the combinational treatment with these two drugs on the extent of atherosclerosis and inflammation of atherosclerotic plaques in our constructed animal model ${ }^{[14]}$. This atherosclerosis model was induced by feeding on a high-cholesterol diet and treating the animals with fluvastatin or losartan or a combination of the two drugs.

We have shown that after treatment of the atherosclerotic rabbits with either fluvastatin or losartan, the severity of atherosclerosis and the number of macrophages in the atherosclerotic plaques decreased. More importantly, treatment of the atherosclerotic rabbits with a combination of fluvastatin and losartan further reduced the severity of atherosclerosis and decreased the number of macrophages and MCP-1 expression compared to the administration of fluvastatin or losartan alone. These results suggested that combinational use of fluvastatin and losartan was more efficient in treating atherosclerosis and inflammation, which ultimately results in the stabilization of the plaques and decreases the occurrence of acute coronary syndrome. Our results are consistent with a previous report ${ }^{[15]}$ in which the combination of pravastatin and captopril further reduced the macrophage-foam cell size and fatty streak area compared to the individual use of either pravastatin or captopril ${ }^{[8]}$. Previous studies showed that the combination of rosuvastatin and candesartan further reduced the severity of atherosclerosis and the expression of lectin-like ox-LDL receptor-1 (LOX-1), which is a receptor for oxidized low-density lipoprotein, compared to the administration of rosuvastatin or candesartan ${ }^{[16]}$ separately in mice.

A growing body of evidence has indicated that lipid metabolism disorders and angiotensin II have a synergistic effect on the occurrence of atherosclerosis. Hypercholesterolemia can up-regulate the expression of AT1R and angiotensin converting enzyme at both the mRNA and protein levels, which increases production of angiotensin $\mathrm{II}^{[17,18]}$. Angiotensin II not only enhances the transformation of LDL to ox-LDL by increasing the production of ROS but also has a direct effect on the ox-LDL receptor, LOX-1 ${ }^{[19]}$. Previous studies have demonstrated that angiotensin II increased the expression of LOX-1 in a dose-dependent manner when coronary endothelial cells were incubated with different concentrations of angiotensin II. In addition, an AT1R blocker (losartan) down-regulated the expression of LOX-1 while an AT2R blocker (PD123319) did not inhibit the expression of LOX-1. These results suggest that angiotensin II-induced expression of LOX-1 is mediated by $\mathrm{AT}_{1} \mathrm{R}^{[20]}$. Further studies have shown that angiotensin II can activate NF-kappaB, which in turn activates the promoter of the LOX-1 gene and up-regulates the transcription of LOX-1 ${ }^{[21]}$. Chen $\mathrm{J}$ et al showed that rosuvastatin and candesartan alone had inhibitory effects on LOX-1 expression in the atherosclerotic plaques, whereas a combination had a dramatic inhibitory effect on LOX-1 expression. In addition, the author demonstrated that the combination of a statin and an AT1R blocker inhibited p38 mitogen-activated protein kinase (MAPK) expression, which indicates that the antiatherosclerotic effect of combination therapy may be due to the inhibition of LOX-1 protein expression and p38 MAPK expression ${ }^{[15]}$.

MCP-1 is an important chemokine and plays a critical role in monocyte aggregation. Previous studies showed that statins (eg, simvastatin) significantly reduced the MCP-1 level in monocytes in vitro ${ }^{[12]}$. In addition, angiotensin II receptor blockers (eg, irbesartan) can also decrease the expression of MCP-1 and relieve the extent of atherosclerotic plaques ${ }^{[22,23]}$. However, less synergistic effects on the expression of MCP-1 were observed by the combination of statins and ARB. Our current study further explored the effects of a combination of fluvastatin and losartan on the expression of MCP-1 to identify the potential anti-inflammatory mechanisms. Our results showed that a combination of fluvastatin and losartan further reduced the expression of MCP-1 on both the gene and protein levels compared to individual treatment with either fluvastatin or losartan. Because the aggregation of inflammatory cells is a consequence of multiple factors, decreased expression of MCP-1 might only represent one of the mechanisms by which combinational treatment exerts its additive anti-inflammatory effects.

The activation of p38 MAPK by ox-LDL and angiotensin II in vascular smooth muscle cells has been reported. It was found that the activation of p38 MAPK was involved in the ox-LDL- and angiotensin II-induced up-regulation of MCP-1 in vascular endothelial cells and in hyperlipidemia-induced atherosclerosis. Our study found that while fluvastatin and losartan alone could significantly decrease p38 MAPK expression and phosphorylation, a combination of the two drugs demonstrated a synergistic effect. Our results suggest that decreased p38 MAPK expression and phosphorylation as a result of combinational treatment may play an important role 
A

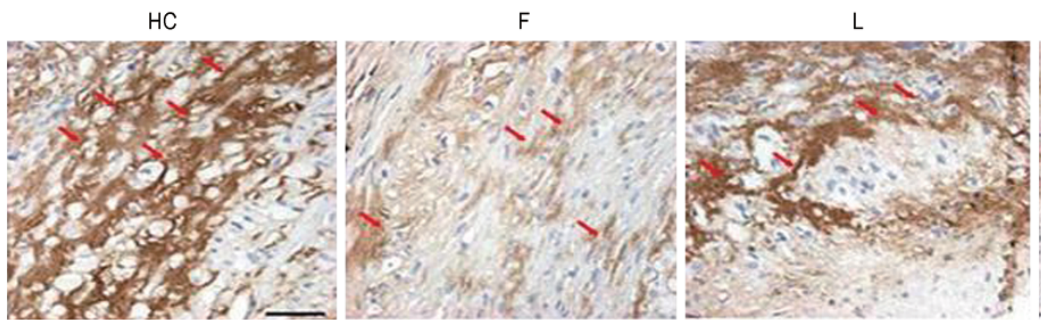

$\mathrm{F}+\mathrm{L}$

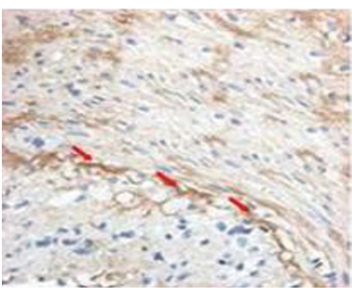

B

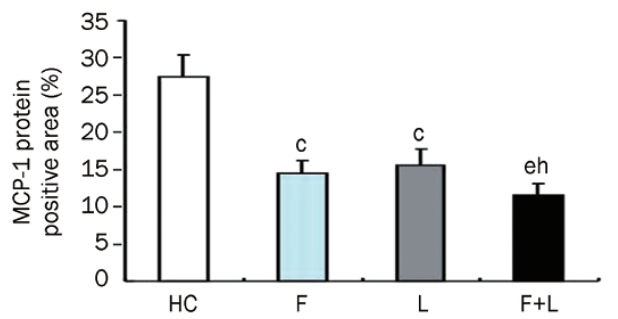

C

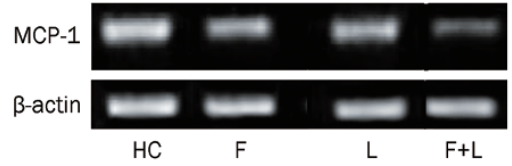

D

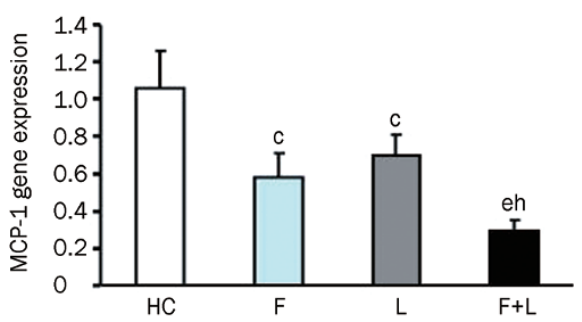

Figure 4. MCP-1 protein and gene expression in the four groups. (A) MCP-1 protein expression in the four groups by immunohistochemical staining (magnification $\times 40$, scale bars equal $50 \mu \mathrm{m}$ ). (B) Quantification of the MCP-1 protein level by immunohistochemical staining in the four groups. (C) MCP-1 mRNA expression levels by RT-PCR in the four groups. (D) Quantification of MCP-1 mRNA levels by RT-PCR in the four groups. ${ }^{\circ} P<0.01$ vs HC-diet group; ${ }^{\mathrm{e}} P<0.05$ vs fluvastatin group; ${ }^{\mathrm{h}} P<0.05$ vs losartan group. Mean \pm SD. $n=9$.

A

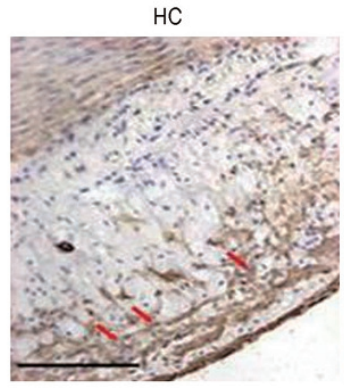

B

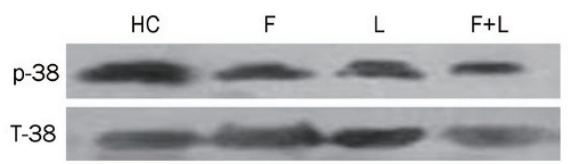

$\mathrm{F}$
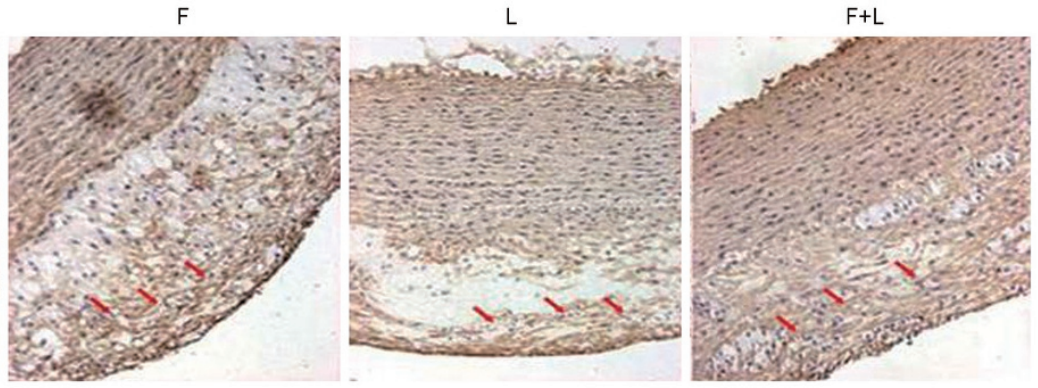

C

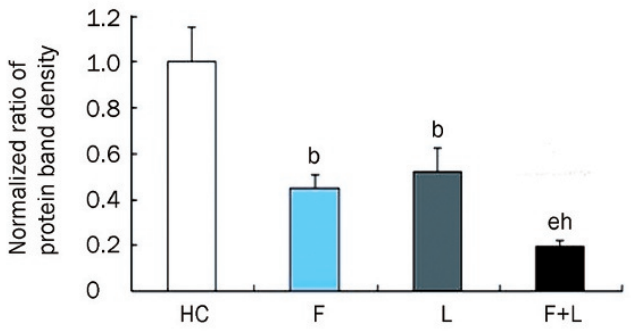

Figure 5. Vascular smooth muscle cells (SMCs) and p38 MAPK protein expression in the four groups. (A) SMCs expression in the four groups by immunohistochemical staining (magnification $\times 20$, scale bars equal $200 \mu \mathrm{m}$ ). There was no difference among the four groups. (B) p38 MAPK protein expression in the four groups by Western blot. (C) Quantification of p38 MAPK protein level by Western blot in the four groups. ${ }^{\mathrm{b}} P<0.05 \mathrm{vs} \mathrm{HC}$-diet group. ${ }^{e} P<0.05$ vs fluvastatin group. ${ }^{\text {h}} P<0.05$ vs losartan group. Mean \pm SD. $n=9$. 
in inhibiting atherosclerosis.

In conclusion, our studies showed that the combination of fluvastatin and losartan further reduced the severity of atherosclerosis compared to the individual use of either fluvastatin or losartan. These results demonstrated that a synergistic antiinflammatory effect is mediated by the combinational use of fluvastatin and losartan by inhibiting RAS and p38 MAPK expression and phosphorylation. This combination therapy may play an important role in preventing the progression of coronary heart disease.

\section{Acknowledgements}

This work was supported by National Natural Science Foundation of China (№ 81170207) and the Program of Introducing Talents of Discipline to Universities (No B07035) and Shandong Natural Science Foundation of China (Nos 03BS37 and Y2006C68). We thank Rong WANG, Yong-huan ZHANG, and Xu-ping WANG for their technical assistance.

\section{Author contribution}

Ya-pei YANG, Qiu-li DONG, Bo DONG, Yue-hui ZHANG, and Li ZHU performed research; Xu-hong ZHANG, Zhongzhi LIU, Hui XU, Hong JIANG, and Chun-xi LIU participated in drug administration and the construction of atherosclerosis model; Shu-ying LI and Nan WANG contributed analytic tools; Ya-pei YANG, Qiu-li DONG, and Bo DONG analyzed data; and Ya-pei YANG, Qiu-li DONG, Bo DONG, and Xian-xi LIU wrote the paper.

\section{References}

1 Graninger M, Reiter R, Drucker C, Minar E, Jilma B. Angiotensin receptor blockade decreases markers of vascular inflammation. J Cardiovasc Pharmacol 2004; 44: 335-9.

2 Heeba G, Moselhy ME, Hassan M, Khalifa M, Gryglewski R, Malinski T. Anti-atherogenic effect of statins: role of nitric oxide, peroxynitrite and haem oxygenase-1. Br J Pharmacol 2009; 156: 1256-66.

3 Singh BM, Mehta JL. Interactions between the renin-angiotensin system and dyslipidemia. Arch Intern Med 2003; 163: 1296-304.

4 Gómez-Garre D, Muñoz-Pacheco P, González-Rubio ML, Aragoncillo P, Granados R, Fernández-Cruz A. Ezetimibe reduces plaque inflammation in a rabbit model of atherosclerosis and inhibits monocyte migration in addition to its lipid-lowering effect. Br J Pharmacol 2009; 156: 1218-27.

5 Chen HJ, Li DY, Saldeen T, Phillips MI, Mehta JL. Attenuation of tissue P-selectin and MCP-1 expression and intimal proliferation by $\mathrm{AT}_{1}$ receptor blockade in hyperlipidemic rabbits. Biochem Biophys Res Commun 2001; 282: 474-9.

6 Marcu L, Fang Q, Jo JA, Papaioannou T, Dorafshar A, Reil T, et al. In vivo detection of macrophages in a rabbit atherosclerotic model by time-resolved laser-induced fluorescence spectroscopy. Atherosclerosis 2005; 181: 295-303.

7 Dong B, Zhang C, Feng JB, Zhao YX, Li SY, Yang YP, et al. Overexpression of ACE2 enhances plaque stability in a rabbit model of atherosclerosis. Arterioscler Thromb Vasc Biol 2008; 28: 1270-6.

8 Zhang C, Zhao YX, Zhang YH, Zhu L, Deng BP, Zhou ZL, et al.
Angiotensin-converting enzyme 2 attenuates atherosclerotic lesions by targeting vascular cells. Proc Natl Acad Sci U S A 2010; 107: 15886-91.

9 Han SH, Koh KK, Quon MJ, Lee Y, Shin EK. The effects of simvastatin, losartan, and combined therapy on soluble CD40 ligand in hypercholesterolemic, hypertensive patients. Atherosclerosis 2007; 190: 205-11.

10 Koh KK, Quon MJ, Han SH, Chung WJ, Ahn JY, Seo YH, et al. Additive beneficial effects of losartan combined with simvastatin in the treatment of hypercholesterolemic, hypertensive patients. Circulation 2004; 110: 3687-92.

11 Kim Y, Park K, Kang W. Effect of fluvastatin, lovastatin, nifedipine and verapamil on the systemic exposure of nateglinide in rabbits. Biopharm Drug Dispos 2010; 31: 443-9.

$12 \mathrm{Hu}$ MY, Li YL, Jiang CH, Liu ZQ, Qu SL, Huang YM. Comparison of lycopene and fluvastatin effects on atherosclerosis induced by a high-fat diet in rabbits. Nutrition 2008; 24: 1030-8.

13 Ruan LM, Cai W, Chen JZ, Duan JF. Effects of losartan on expression of connexins at the early stage of atherosclerosis in rabbits. Int J Med Sci 2010; 7: 82-9.

14 Boban PT, Nambisan B, Sudhakaran PR. Dietary mucilage promotes regression of atheromatous lesions in hypercholesterolemic rabbits. Phytother Res 2009; 23: 725-30.

15 Chen J, Li D, Schaefer R, Mehta JL. Cross-talk between dyslipidemia and renin-angiotensin system and the role of LOX-1 and MAPK in atherogenesis studies with the combined use of rosuvastatin and candesartan. Atherosclerosis 2006; 184: 295-301.

16 Zhong L, Chen WQ, Ji XP, Zhang M, Zhao YX, Yao GH, et al. Dominantnegative mutation of monocyte chemoattractant protein-1 prevents vulnerable plaques from rupture in rabbits independent of serum lipid levels. J Cell Mol Med 2008; 12: 2362-71.

17 Sun YP, Zhu BQ, Browne AE, Pulukurthy S, Chou TM, Sudhir K, et al. Comparative effects of ACE inhibitors and an angiotensin receptor blocker on atherosclerosis and vascular function. J Cardiovasc Pharmacol Ther 2001; 6: 175-81.

18 Chatzizisis YS, Jonas M, Beigel R, Coskun AU, Baker AB, Stone BV, et al. Attenuation of inflammation and expansive remodeling by valsartan alone or in combination with simvastatin in high-risk coronary atherosclerotic plaques. Atherosclerosis 2009; 203: 387 94.

19 Ge J, Huang D, Liang C, Luo Y, Jia Q, Wang K. Upregulation of lectinlike oxidized low-density lipoprotein receptor-1 expression contributes to the vein graft atherosclerosis: modulation by losartan. Atherosclerosis 2004; 177 : 263-8.

20 Xu HX, Li JJ, Li GS, Wang J, Li NX, Peng J. Decreased infiltration of macrophages and inhibited activation of nuclear factor-kappa B in blood vessels: a possible mechanism for the anti-atherogenic effects of losartan. Acta Cardiol 2007; 62: 607-13.

21 Imanishi T, Kuroi A, Ikejima H, Kobayashi K, Muragaki Y, Mochizuki S, et al. Effects of angiotensin converting enzyme inhibitor and angiotensin II receptor antagonist combination on nitric oxide bioavailability and atherosclerotic change in Watanabe heritable hyperlipidemic rabbits. Hypertens Res 2008; 31: 575-84.

22 Chen J, Liu Y, Liu H, Hermonat PL, Mehta JL. Molecular dissection of angiotensin II-activated human LOX-1 promoter. Arterioscler Thromb Vasc Biol 2006; 26: 1163-8.

23 Soufi M, Sattler AM, Maisch B, Schaefer JR. Molecular mechanisms involved in atherosclerosis. Herz 2002; 27: 637-48. 